\title{
PENGAPLIKASIAN PETA KENDALI $P$ BAYES PADA DATA KASUS DI PT. XYZ
}

\author{
FITARI RESMALANI, FERRA YANUAR, DODI DEVIANTO \\ Program Studi S1 Matematika, \\ Fakultas Matematika dan Ilmu Pengetahuan Alam, Universitas Andalas, \\ Kampus UNAND Limau Manis, Padang, Indonesia \\ fitariresmalani@gmail.com,ferrayanuar@sci.unand.ac.id,ddevianto@sci.unand.ac.id
}

Diterima 17 Februari 2020 Direvisi 7 Maret $2020 \quad$ Dipublikasikan 29 April 2020

\begin{abstract}
Abstrak. Kualitas dijadikan suatu hal utama yang perlu diperhatikan karena kualitas tidak dapat dipisahkan dalam pengendalian produksi. Salah satu alat statistika yang digunakan untuk mengetahui apakah suatu proses produksi dalam keadaan terkendali yaitu peta kendali. Pada penelitian ini menggunakan peta kendali atribut dengan distribusi Binomial atau biasa disebut sebagai peta kendali $p$ yang kemudian diduga menggunakan metode klasik dan metode Bayes. Data yang digunakan merupakan data sekunder pada PT. XYZ. Pada pengaplikasiannya, saat menggunakakan peta kendali $p$ klasik tidak ditemukan data yang diluar batas kendali, sedangkan saat menggunakan peta kendali $p$ Bayes terdapat sampel yang berada diluar batas kendali. Hal ini dikarenakan lebar selang pada Bayes lebih kecil.
\end{abstract}

Kata Kunci: Peta Kendali p, metode Bayes, metode klasik

\section{Pendahuluan}

Saat ini dalam perkembangan dunia industri, kualitas dijadikan suatu hal utama yang perlu diperhatikan karena kualitas tidak dapat dipisahkan dalam pengendalian produksi. Pengawasan kualitas sangat dibutuhkan oleh tiap perusahaan dalam menambah atau mempertahankan pasar perusahaan. Oleh karena itu, penting adanya suatu pengendalian agar tercapainya standar kualitas yang diinginkan. Salah satu alat statistika yang digunakan untuk mengetahui apakah suatu proses produksi dalam keadaan terkendali yaitu peta kendali.

Peta kendali terbagi menjadi dua golongan, yaitu peta kendali variabel dan peta kendali atribut. Peta kendali memiliki batas-batas yang menunjukkan proses berjalan memenuhi standar atau belum. Peta kendali atribut terbagi lagi menjadi dua macam distribusi, yaitu distribusi Poisson dan distribusi Binomial. Peta kendali atribut yang berdistribusi Binomial disebut peta kendali $p$. Pada peta kendali $p$ terdapat batas pengendali atas dan batas pengendali bawah yang dilakukan dengan

*penulis korespondensi 
pendekatan distribusi Normal terhadap distribusi Binomial. Sementara itu, untuk titik-titik yang diplot merupakan data karakteristik kualitas dari setiap sampel, yaitu banyaknya proporsi ketidaksesuian pada setiap sampel sehingga setiap sampel yang diplot tidak bergantung dengan sampel sebelumnya[4].

Pada penelitian ini akan dilakukan pendugaan parameter untuk memperoleh batas-batas pengendali dari peta kendali $p$. Metode yang dapat digunakan untuk menduga parameter yaitu metode klasik dan metode Bayes. Perbedaan metode klasik dan metode Bayes adalah pada metode klasik, kesimpulan sepenuhnya dari data sampel yang diambil dari populasi, sedangkan pada metode Bayes kesimpulan diambil dengan menggabungkan informasi dari data sampel yang berasal dari populasi serta distribusi awal terkait parameter yang akan diestimasi atau biasa disebut sebagai distribusi prior[6]. Gabungan tersebut kemudian akan membentuk suatu distribusi baru yang disebut sebagai distribusi posterior, sehingga dalam hal ini nilai dugaan parameter yang dihasilkan dari metode Bayes akan lebih mendekati nilai yang sebenarnya dibandingkan dengan metode klasik.

\section{Landasan Teori}

\subsection{Pengendalian Mutu Statistik}

Pengendalian mutu statistik adalah salah satu teknik yang digunakan untuk mengendalikan, memonitor, mengelola, menganalisa, dan memperbaiki suatu proses dengan menggunakan metode statistik. Salah satu alat statistik yang digunakan untuk menentukan apakah proses dalam keadaan terkendali yaitu peta kendali.Peta kendali yang dikembangkan oleh Walter Shewhart dikenal dengan sebutan bagan kendali Shewhart [5]. Pada peta kendali biasanya dipilih batas toleransi sebesar tiga kali standar deviasi agar memperoleh kepercayaan sebesar 99,73\% untuk mengetahui apakah suatu produksi berada dalam batas kendali atau tidak [3].

\subsection{Peta Kendali p klasik}

Peta kendali $p$ didefenisikan sebagai perbandingan banyaknya produk yang tidak sesuai dalam suatu subgrup. Peta kendali $p$ dikembangkan berdasarkan peta kendali Shewhart sehingga diperlukan mean dan standar deviasi dari $p$ untuk membentuknya. Asas statistik yang melandasi pada peta kendali $p$ yaitu distribusi Binomial. Rumusan untuk membuat peta kendali $p$ sebagi berikut:

$$
p_{i}=\frac{r_{i}}{n_{i}}
$$

dengan

$\mathrm{p}$ : proporsi kerusakan,

$\mathrm{r}$ : jumlah produk yang tidak sesuai,

$\mathrm{n}$ : jumlah sampel,

sehingga, dapat dihitung.

$$
\bar{p}=\frac{r}{n}=\frac{\sum_{i=1}^{k} r_{i}}{\sum_{i=1}^{k} n_{i}},
$$


164 Fitari Resmalani, dkk.

$$
\sigma=\sqrt{\frac{\bar{p}(1-\bar{p})}{n}},
$$

dengan

$\bar{p}$ : rata-rata proporsi kerusakan,

$\sigma$ : standar deviasi proporsi kerusakan,

sehingga dapat diperoleh:

$$
\begin{gathered}
C L=\bar{p}, \\
L C L=\bar{p}-3 \sigma=\bar{p}-3 \sqrt{\frac{\bar{p}(1-\bar{p})}{n}}, \\
\bar{p}+3 \sigma=\bar{p}+3 \sqrt{\frac{\bar{p}(1-\bar{p})}{n}},
\end{gathered}
$$

yang kemudian akan digunakan untuk batas pengendali dalam membuat peta kendali $p$ klasik [4].

\subsection{Peta Kendali p Bayes}

Pada peta kendali $p$ Bayes, nilai CL, UCL, dan LCL akan diestimasi dengan menggunakan metode Bayes. Misalkan $R=r_{1}, r_{2}, \cdots, r_{k}$ merupakan banyaknya kejadian dalam $k$ percobaan, $n$ sampel, dan $p$ adalah nilai kemungkinan suatu kejadian. Banyaknya produksi yang tidak sesuai pada setiap mengambil sampel ukuran $n$ yaitu $X_{1}, X_{2}, \cdots, X_{n}$, dimana $X_{i} \sim \operatorname{Binomial}(1, \mathrm{p})$ dengan $p \in \Omega(0,1)$, maka fungsi kepekatan peluangnya adalah [2]:

$$
f\left(x_{i} ; p\right)=p^{x_{i}}(1-p)^{1-x_{i}}, x_{i}=(0,1)
$$

dan fungsi likelihoodnya adalah:

$$
\begin{aligned}
L(p) & =\Pi_{i=1}^{n} f\left(x_{i} ; p\right) \\
& =\Pi_{i=1}^{n} p^{x_{i}}(1-p)^{1-x_{i}} \\
& =\Pi_{i=1}^{n} p^{\Sigma_{i=1}^{n} x_{i}}(1-p)^{n-x_{i}} \\
& =\Pi_{i=1}^{n} p^{r}(1-p)^{n-r},
\end{aligned}
$$

dengan $R=\sum_{i=1}^{n} X_{i} \sim \operatorname{Binomial}(n, p)$.

Distribusi Beta merupakan keluarga eksponensial dari distribusi Binomial, sehingga distribusi Beta dapat digunakan sebagai prior konjugat dari distribusi Binomial. Selain itu, parameter $p$ dalam distribusi Beta sebagai penduga yang tidak diketahui merupakan peluang banyaknya produk yang tidak sesuai dalam distribusi 
Binomial yang hanya memiliki nilai antara 0 sampai 1. Karena itu, digunakannya Beta sebagai distribusi prior dengan mengasumsikan bahwa parameter $p$ dapat menjalani banyaknya tak hingga nilai-nilai bilangan riil dari 0 sampai 1 [1].

Dengan demikian distribusi Prior untuk $p$ yaitu distribusi $\operatorname{Beta}(\alpha, \beta)$ yang memiliki bentuk fungsi kepekatan peluang sebagai berikut:

$$
\begin{aligned}
f(p) & =\frac{\Gamma(\alpha+\beta)}{\Gamma(\alpha) \Gamma(\beta)} p^{\alpha-1}(1-p)^{\beta-1}, \text { untuk } 0<p<1 . \\
& \propto p^{\alpha-1}(1-p)^{\beta-1} .
\end{aligned}
$$

Pada metode Bayes, distribusi $\operatorname{Beta}(\alpha, \beta)$ sebagai distribusi prior konjugat merupakan distribusi yang mempresentasikan keyakinan terhadap parameter sehingga diperlukannya pertimbangan dalam menentukan parameter $\alpha$ dan $\beta$. Distribusi prior $\operatorname{Beta}(\alpha, \beta)$ dapat ditentukan dengan mencocokkan mean dan standar deviasi. Jika diketahui proporsi $p$ dalam suatu percobaan Binomial $p=\frac{r}{n}$, sehingga diperoleh paramaeter beta yaitu $\alpha=\frac{R(n-1)}{n}$ dan $\beta=\frac{(n-R)(n-1)}{n}$. Parameter Beta tersebut nantinya akan digunakan untuk batas pengendali pada peta kendali Bayes.

Distribusi Posterior dapat diperoleh dengan

$$
\begin{aligned}
f(p \mid r) & =\frac{f(p) L(p)}{\int_{-\infty}^{\infty} f(p) L(p) d p} \\
& =\frac{\Gamma(\alpha+n+\beta)}{\Gamma(r+\alpha) \Gamma(n-r+\beta)} p^{r+\alpha-1}(1-p)^{n-r+\beta-1}
\end{aligned}
$$

dengan memisalkan $\alpha^{\prime}=r+\alpha$ dan $\beta=n-r+\beta$ maka distribusi posterior ini berasal dari distribusi $\operatorname{Beta}\left(\alpha^{\prime}, \beta^{\prime}\right)$ atau dapat dinotasikan dengan[1]:

$$
P \mid R \sim \operatorname{Beta}(R+\alpha, n-R+\beta)
$$

Berdasarkan distribusi posterior tersebut, maka dapat diperoleh

$$
\mu=\frac{R+\alpha}{\alpha+\beta+n} .
$$

dan

$$
\sigma=\sqrt{\frac{(R+\alpha)(n-R+\beta)}{(\alpha+\beta+n+1)(\alpha+\beta+n)^{2}}}
$$

sehingga batas pengendali pada peta kendali $p$ Bayes yaitu

$$
C L=\mu=\frac{R+\alpha}{\alpha+\beta+n} .
$$




$$
\begin{aligned}
& L C L=\mu-3 \sigma=\frac{R+\alpha}{\alpha+\beta+n}-3 \sqrt{\frac{(R+\alpha)(n-R+\beta)}{(\alpha+\beta+n+1)(\alpha+\beta+n)^{2}}} . \\
& U C L=\mu+3 \sigma=\frac{R+\alpha}{\alpha+\beta+n}+3 \sqrt{\frac{(R+\alpha)(n-R+\beta)}{(\alpha+\beta+n+1)(\alpha+\beta+n)^{2}}} .
\end{aligned}
$$

yang kemudian akan digunakan untuk batas pengendali dalam membuat peta kendali $p$ Bayes.

\section{Pembahasan}

Pada bagian ini akan diilustrasikan contoh penerapan dari peta kendali $p$ klasik dan peta kendali $p$ Bayes. Data diambil dari PT. XYZ dengan sampel sebanyak $i=34$ dengan $n_{i}$ menyatakan banyaknya produksi pada sampel, $r_{i}$ menyatakan banyaknya produksi sampel yang tidak sesuai dan $p_{i}$ menyatakan proporsi sampel yang tidak sesuai. Berikut adalah data PT.XYZ pada Tabel 1.

\begin{tabular}{|c|c|c|c|c|c|c|c|}
\hline $\begin{array}{l}\text { Nomor } \\
\text { Sampel } \\
\quad(i)\end{array}$ & $\begin{array}{l}\text { Banyak } \\
\text { Produksi } \\
\quad\left(\boldsymbol{n}_{i}\right)\end{array}$ & $\begin{array}{c}\text { Banyaknya } \\
\text { produksi } \\
\text { Sampel yang } \\
\text { tidak sesuai } \\
\left(r_{i}\right)\end{array}$ & $\begin{array}{c}\text { Proporsi } \\
\text { Sampel } \\
\left(p_{i}\right)\end{array}$ & $\begin{array}{l}\text { Nomor } \\
\text { Sampel } \\
\quad(i)\end{array}$ & $\begin{array}{l}\text { Banyak } \\
\text { Produksi } \\
\quad\left(\boldsymbol{n}_{i}\right)\end{array}$ & $\begin{array}{c}\text { Banyaknya } \\
\text { produksi } \\
\text { Sampel yang } \\
\text { tidak sesuai } \\
\left(r_{i}\right)\end{array}$ & $\begin{array}{c}\text { Proporsi } \\
\text { Sampel } \\
\qquad\left(p_{i}\right)\end{array}$ \\
\hline 1 & 1565 & 8 & 0.00503 & 18 & 1766 & 15 & 0.00845 \\
\hline 2 & 1488 & 6 & 0.00393 & 19 & 662 & 3 & 0.00498 \\
\hline 3 & 1373 & 9 & 0.00623 & 20 & 768 & 4 & 0.00518 \\
\hline 4 & 2362 & 15 & 0.00623 & 21 & 1939 & 8 & 0.00421 \\
\hline 5 & 682 & 5 & 0.00711 & 22 & 2035 & 12 & 0.00588 \\
\hline 6 & 1306 & 10 & 0.00729 & 23 & 1315 & 6 & 0.00481 \\
\hline 7 & 1613 & 14 & 0.00859 & 24 & 1133 & 5 & 0.0048 \\
\hline 8 & 442 & 3 & 0.00778 & 25 & 1709 & 5 & 0.00282 \\
\hline 9 & 1507 & 7 & 0.00465 & 26 & 1334 & 7 & 0.0051 \\
\hline 10 & 1901 & 7 & 0.00378 & 27 & 2016 & 17 & 0.00838 \\
\hline 11 & 1546 & 17 & 0.01085 & 28 & 672 & 2 & 0.00261 \\
\hline 12 & 758 & 4 & 0.00568 & 29 & 1498 & 8 & 0.00544 \\
\hline 13 & 509 & 5 & 0.0095 & 30 & 1488 & 7 & 0.00468 \\
\hline 14 & 566 & 5 & 0.0085 & 31 & 1219 & 6 & 0.00475 \\
\hline 15 & 1286 & 6 & 0.00482 & 32 & 2659 & 15 & 0.0055 \\
\hline 16 & 922 & 4 & 0.00401 & 33 & 2592 & 14 & 0.00529 \\
\hline 17 & 1382 & 8 & 0.00606 & 34 & 1373 & 6 & 0.00471 \\
\hline
\end{tabular}

Tabel 4.1 Data PT. XYZ

\subsection{Grafik Peta Kendali p Klasik}

Dari data pada Tabel 1 dapat diperoleh grafik peta kendali $p$ klasik sebagai berikut pada Gambar 1.

Berdasarkan Gambar 1 diketahui bahwa tidak terdapat sampel yang berada diluar batas pengendali atas maupun berada diluar batas pengendali bawah. 


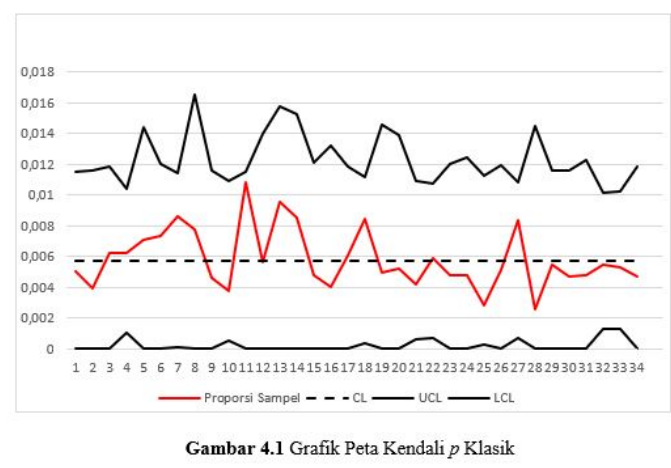

Karena, pada sampel terdapat nilai $L C L<0$, maka diberlakukan $L C L=0$ sehingga dapat dilihat bahwa grafik peta kendali $p$ klasik menjadi tidak simetris.

\subsection{Grafik Peta Kendali p Bayes}

Dari data pada Tabel 1 , diketahu $R=r_{1}, r_{2}, \cdots, r_{k}$ menyatakan banyaknya kejadian dalam $k$ percobaan, $n_{i}$ menyatakan banyaknya sampel, dan $p$ menyatakan proporsi dari banyaknya produk yang tidak sesuai dalam $k$ percobaan. Banyaknya produksi yang tidak sesuai pada setiap mengambil sampel ukuran $n$ yaitu $X_{1}, X_{2}, \cdots, X_{n}$, dimana $X_{i} \sim \operatorname{Binomial}(1, \mathrm{p})$ dengan $p \in \Omega(0,1)$, maka fungsi kepekatan peluangnya seperti persamaan (2.7) dan fungsi likelihoodnya seperti persamaan (2.8). Sehingga dari Tabel 1, dapat diperoleh grafik seperti berikut:

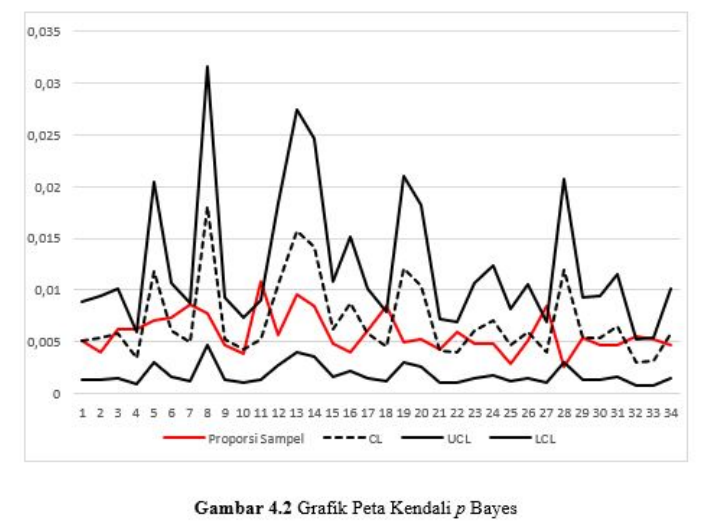

Berdasarkan Gambar 2 dapat dilihat bahwa terdapat beberapa sampel yang berada dalam keadaan tidak terkendali. Adapun sampel-sampel yang tidak terkendali tersebut adalah sampel ke 4, 11, 18, 27, 28, dan 32 .

\subsection{Perbandingan peta kendali $p$ klasik dan peta kendali $p$ Bayes}

Dapat dilihat dari Gambar 1 dan Gambar 2 bahwa peta kendali $p$ Bayes mendeteksi lebih banyak sampel yang berada dalam keadaan tidak terkendali dibandingkan 
dengan peta kendali $p$ klasik. Hal ini disebabkan proses pendugaan parameter pada Bayes mempertimbangkan dua hal, yaitu sebaran dari data dan informasi subjektif terkait parameter yang akan diduga, sehingga menyebabkan nilai dugaan yang dihasilkan pada meode Bayes cenderung menghasilkan nilai yang mendekati ke nilai yang sebenarnya dengan nilai variansi yang cenderung lebih kecil. Oleh karena itu, nilai dugaan selang (dalam hal ini adalah batas-batas kendali) yang dihasilkan pada metode Bayes cenderung akan lebih kecil dibandingkan dengan menggunakan metode klasik.

\section{Kesimpulan}

Pada peta kendali $p$ klasik tidak terdapat data yang berada diluar batas kendali, sedangkan pada peta kendali $p$ Bayes terdapat beberapa sampel yang berada diluar batas kendali. Hal ini dikarenakan pada metode Bayes, lebar selang pada batasbatas kendali yang dihasilkan lebih kecil dibandingkan dengan menggunakan metode klasik.

\section{Ucapan Terimakasih}

Terimakasih kepada Ibu Maiyastri, Ibu Hazmira Yozza dan Bapak Mahdhivan Syafwan yang telah memberikan masukan dan saran sehingga penelitian ini dapat diselesaikan dengan baik.

\section{Daftar Pustaka}

[1] Andrea, O., Erick, O., Joseph, O., 2017, Posterior Distribution Of BetaBinomial Mixture Based On Beta II As Prior Distribution, Research Journal Journal of Mathematics, Vol.4 No.4

[2] Asmara, S.S., Adi S., Mahatma,T., 2012, Penggunaan Metode Bayesian Subjektif dalam Pengkonstruksian Grafik Pengendali-p, Prosiding ISBN 978-97916353-8- $7,116-123$

[3] Grant, E.L., Leavenworth, R.S., Alih Bahasa oleh Kandahjaya, Hudaya., 1996, Pengendalian Mutu Statistis, Jakarta, Penerbit Erlangga

[4] Montgomery, D.C., 1990, Introduction to Statistical Quality Control, 2009, America, A John Wiley \& Sons, Inc

[5] Putri, RR., Yanuar,F., Devianto, D., 2016, Pengendalian Mutu Produksi Berat Semen PT. Semen Padang dengan Bagan Kendali Shewhart dan Robust, Jurnal Matematika UNAND, Vol. 5 No. 1 Hal. $74-81$

[6] Walpole, R.E., R.H Myers, 1995, Ilmu Peluang dan Statistika untuk Insinyur dan Ilmuwan, Edisi Keempat, ITB, Bandung. 